\title{
STUDIES OF GRAVITY WAVES AT FERRAZ STATION (62 S) AND RECENT OBSERVATIONS
}

\author{
http://dx.doi.org/10.4322/apa.2014.019 \\ José Valentin Bageston ${ }^{1, *}$, Paulo Prado Batista1, Cristiano Max Wrasse ${ }^{2}$, Delano Gobbi ${ }^{1}$, \\ Neusa M. Paes Leme ${ }^{1}$, Robert Hibbins ${ }^{3,4}$, David Fritts ${ }^{5}$ \\ 'Instituto Nacional de Pesquisas Espaciais, São José dos Campos, SP, Brazil \\ ${ }^{2}$ Vale Soluções em Energia, São José dos Campos, SP, Brazil \\ ${ }^{3}$ British Antarctic Survey, Cambridge, United Kingdom \\ ${ }^{4}$ Norwegian University of Science and Technology, Trondheim, Norway \\ ${ }^{5}$ Colorado Research Associates, Boulder, United States of America \\ *e-mail: bageston@gmail.com
}

\begin{abstract}
In this study we will present a brief review of mesospheric gravity waves that have been observed at Comandante Ferraz Antarctica Station, EACF $\left(62.1^{\circ} \mathrm{S}\right.$ and $\left.58.4^{\circ} \mathrm{W}\right)$. First, we will show the main results of a campaign conducted from April to October of 2007, with more than 230 events. The main characteristics of the gravity waves are presented as follows: horizontal wavelengths between 10 and $65 \mathrm{~km}$; periods between 5 and 35 minutes, and phase speed ranging from 5 to $120 \mathrm{~m} / \mathrm{s}$. Later, we will show the recent advances related to the observations of temperature, winds and gravity waves in the Mesosphere and Lower Thermosphere (MLT) over Ferraz station. In this sense, examples of temperature and wind data will be presented. Finally, we will show the partial conclusions and future prospects.
\end{abstract}

Keywords: airglow, gravity waves, temperature, winds

\section{Introduction}

The middle atmosphere is a region rich in chemical interactions and with a large variability in terms of dynamics. A wide variety of structures are found in this region, amongst which can be pointed out the airglow layers, metals layers and, at high latitudes a special type of phenomena known as noctilucent clouds. Recent studies suggest that the increase in the concentration of $\mathrm{CO}$ and $\mathrm{CH}$ during this century can result in significant changes in temperature, density and composition of the atmosphere. Thus, the middle atmosphere has received considerable attention mainly due to the circulation system and global climate change (Gardner, 1995). Considerable progress has been made in the last decades in the study and understanding of the phenomenon of gravity waves in the middle atmosphere (Fritts \& Alexander, 2003). Gravity waves are found primarily in the lower atmosphere, and can propagate through the atmosphere until they reach the region of the mesosphere and lower thermosphere (70-100 km height). These waves occur as a result of a displacement of air masses, caused by cold fronts, winds blowing over mountains or by jet streams in the stratosphere. Gravity waves are well known and studied in the meteorology field. However, this phenomenon has received great attention due to its important role in the transporting of energy and momentum from the lower to the upper atmosphere, varying the thermal structure and general circulation in the middle and upper atmosphere (Takahashi et al., 1999). Among the several techniques available for the observation of gravity waves in the middle atmosphere, we can mention meteoric and medium frequency radars, laser techniques, 
in-situ observations by rockets, optical measurements from the ground and from satellites. However, each technique has its own limitation related to the observation of gravity waves and only a fraction of the spectrum of these waves can be solved within a wide spectrum of frequencies and wave number (Nakamura et al., 1999). Thus, the combination of observational methods is very important in order to study the characteristics of gravity waves (Taylor \& Gardner, 1998). This paper presents results from a campaign of atmospheric gravity waves conducted in 2007 at Ferraz station $\left(62.1^{\circ} \mathrm{S}, 58.4^{\circ} \mathrm{W}\right)$. We will also show and discuss briefly some examples of temperature and winds observed at Comandante Ferraz station.

\section{Data and Methodology}

The main data used in this study was from the airglow images, from which it was possible to identify the gravity wave activity in the atmosphere at the altitudes where the airglow emissions occur. In this study, the observed airglow emission is the hydroxyl in the near infrared spectrum (OH NIR, 715-930 nm), with emission peak around $87 \mathrm{~km}$ high. Recently, a meteor radar that operates at a frequency of $36.90 \mathrm{MHz}$ was installed at Comandante Ferraz station with the aim of observing and studying the wind field over the King George Island in the MLT altitude range. The installation and operation of this radar is a collaborative effort between National Institute for Space Research (INPE), Brazil, and Colorado Research Associates (CoRA), United States of America. Simultaneous observations of wind and gravity waves will be valuable to better understand the dynamics of the MLT region on King George Island, and consequently in the Antarctic Peninsula region. Furthermore, the temperature structure in the Mesopause region ( $\sim 87 \mathrm{~km}$ high) has been monitored at Comandante Ferraz station since 2002. Since 2005 an airglow CCD camera that observes the $\mathrm{OH}(6-2)$ emission through an annular field of view of $22.6^{\circ}$ centred at the zenith has been in use.

The methodology used to extract the wave parameters was based on analysis of the airglow all-sky images. This analysis uses the well established Fast Fourier Transform (FFT) technique, but prior to the application of this analysis it was necessary to see the images in an animation ("avi” file format) to identify the gravity waves occurrence, and subsequently select a time interval and a spatial region on the images where each wave was identified. Furthermore, after this pre-visualization, it was necessary to apply a pre-processing of the images before the application of the FFT. The pre-processing basically consists of a rotation in the images in order to align the top to the geographic north, and then mapping the image at the height of the airglow emitting layer to correct the effects of distortion in the images due to the optical system effects. This process is known as linearization, and the corrected images are called unwarp images. The next step is the removal of the stars, followed by a filtering in the images, and finally the FFT analysis can be applied to a chosen region on the image, portion on which a gravity wave event is occurring (identified previously in the "avi" animation). The details of this methodology can be found in the thesis work of Bageston (2010) and in the pertinent references.

\section{Results and Discussion}

The main results already obtained are related to the characterization of gravity waves for those observed in 2007. We will also show some recent observations of winds and gravity waves. The waves characteristics observed at Comandante Ferraz during 2007 were obtained from the analysis of the images observed trough the NIR OH airglow emission, including a total of 234 wave events. Figure 1 shows the observed parameters, that is, the horizontal wavelength, period and phase speed for these waves. The intrinsic parameters were also inferred and showed a similar behaviour to the observed characteristics, but with a maximum occurrence slightly shifted due to the wind effect (Doppler shift).

The horizontal wavelengths were distributed from 10 to $65 \mathrm{~km}$, with a maximum occurrence between 20 and $40 \mathrm{~km}$. The observed periods were mainly distributed between 5 and 35 minutes, but the maximum concentration was between 5 and 15 minutes. The observed phase speed has a distribution that extends from 5 to $120 \mathrm{~m} / \mathrm{s}$. The majority of the waves had velocities between 10 and $70 \mathrm{~m} / \mathrm{s}$. 

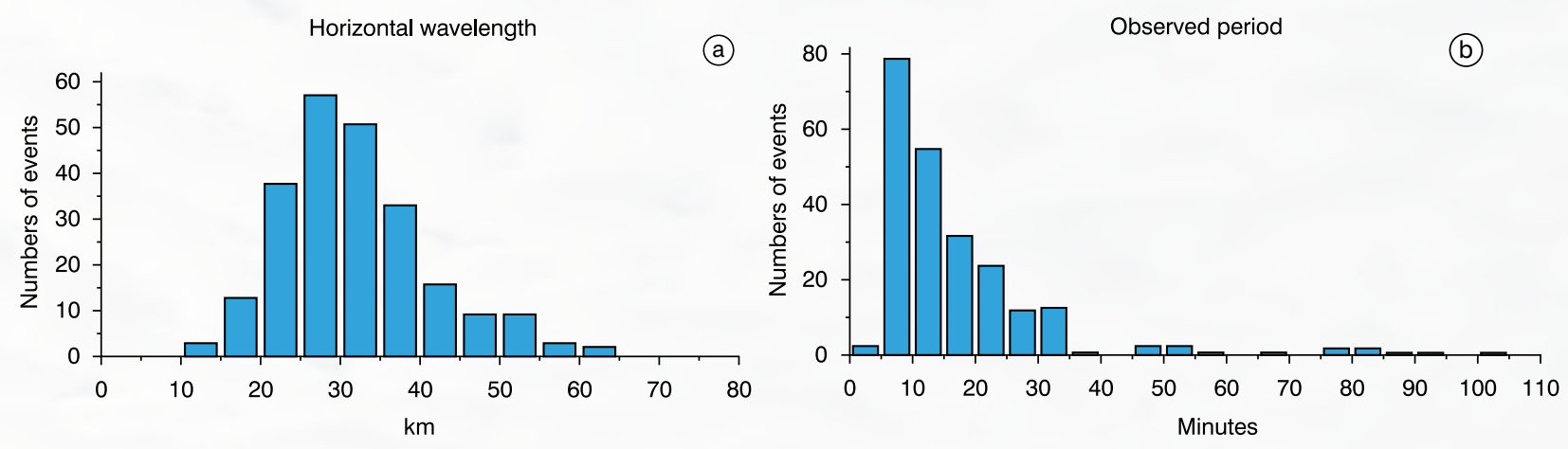

Horizontal phase speed

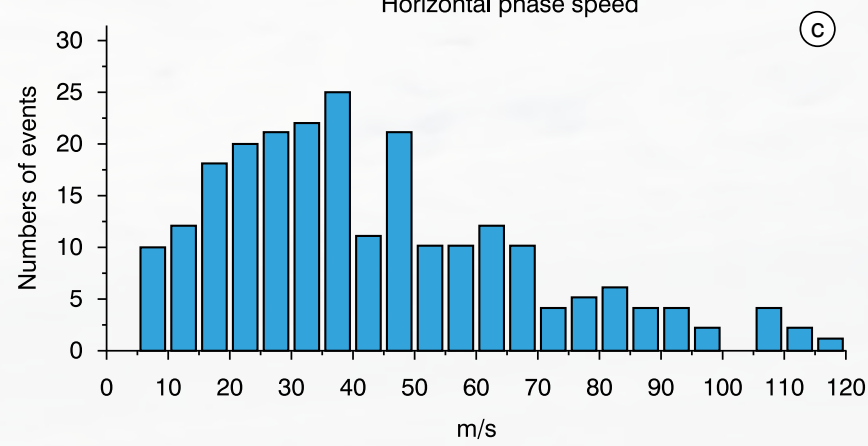

Figure 1. Histogram plots of the gravity wave characteristics observed at Comandante Ferraz station in 2007. The panels show, from top to bottom, the horizontal wavelength, observed period and horizontal phase speed.

The results presented in Figure 1 are very similar to the observations reported in the literature, especially considering the results of observations conducted at other Antarctica stations: Halley ( $76^{\circ} \mathrm{S}$ and $\left.27^{\circ} \mathrm{W}\right)(2000-2001)$ and Rothera (68 $\mathrm{S}$ and $\left.68^{\circ} \mathrm{W}\right)$ (2002-2003) (Nielsen, 2007; Nielsen et al., 2009). The horizontal propagation directions showed an anisotropic behaviour during the winter (Bageston et al., 2009), with similarities to the observations conducted at Rothera and Halley, i.e., with preferential propagation direction to southwest and south (Nielsen, 2007).

Temperature in the MLT region has been monitored at Comandante Ferraz since 2002, and from 2005 with a airglow camera, in order to study effects of gravity waves in this parameter and also to investigate, in the future, the long term variability in the Mesopause region. Figures 2 (a) and (b) shows one example of temperature and airglow intensity, respectively, during one entire night during 2007. The small scale variability in the temperature and $\mathrm{OH}$ intensity during the night could be related to small scale gravity waves. The large and abrupt decrease in the $\mathrm{OH}(6-2)$ intensity and temperature, denoted by the arrows, were related to the passage of a mesospheric wall (extensive gravity wave event) above Ferraz (Bageston et al., 2011).

Recently, gravity wave and wind observations at Comandante Ferraz station are registering good quality recordings, and this data will be used soon for a detailed investigation of the dynamics of the MLT region over Comandante Ferraz. However, this data, including temperature data, are still in Antarctica, and will be sent to Brazil by the end of this year. Fortunately, some examples of winds data were obtained remotely from Comandante Ferraz. Figure 3 shows one example of winds observed during two days, 12-13 September 2010. The main characteristic observed from Figure 3 is the well defined semi-diurnal tide, that is, oscillations in the zonal and meridional wind components over a period of about 12 hours. In addition, it is possible to identify that the winds 


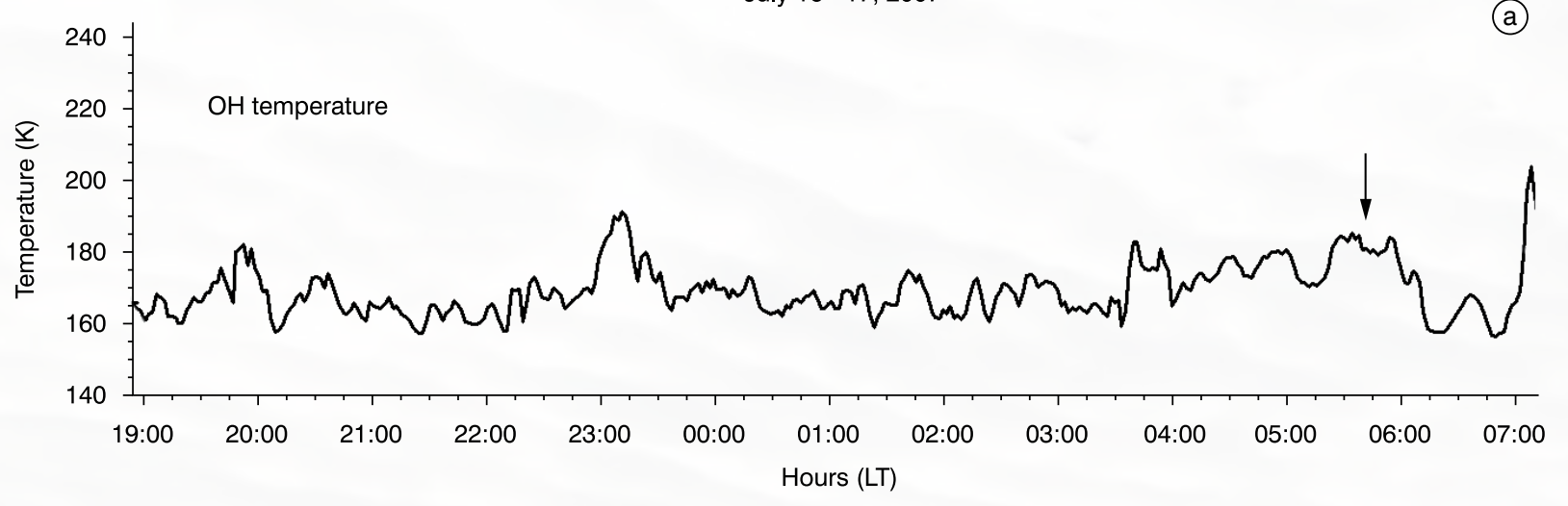

July $16-17,2007$

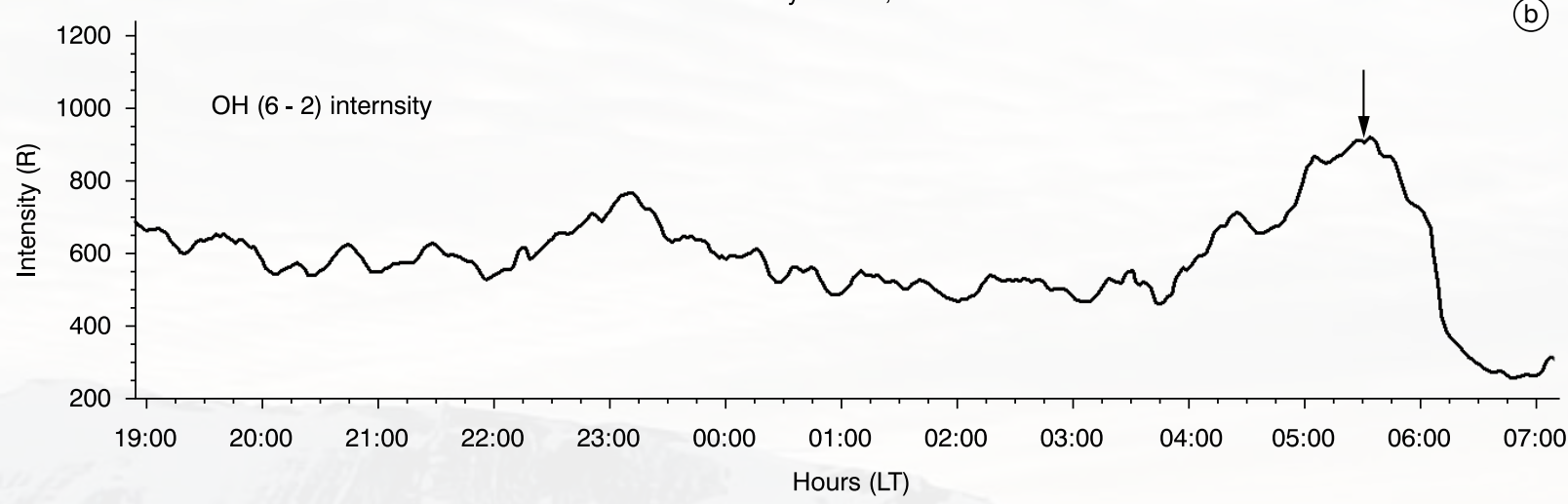

Figure 2. Temperature and $\mathrm{OH}(6-2)$ airglow intensity observed at Comandante Ferraz by an imaging spectrometer on 16-17July 2007.

in the upper altitudes $(94 \mathrm{~km})$ are more intense than at lower altitudes $(85 \mathrm{~km})$.

Gravity wave activity observed last year, by analysing some observed nights, seems to be similar to the activity observed in 2007, but with less useful data in 2010 in comparison to the observations carried out in 2007.

\section{Conclusions and Future Prospects}

In summary, the present study has shown the main characteristics of the gravity waves observed at Comandante Ferraz station in 2007, which were consistent with previous observations in Antarctica, in particular to the wave parameters obtained from the observations at Rothera. Currently, three instruments are in operation at Comandante Ferraz with the objective of studying the dynamics and the thermal structure of the mesosphere and lower thermosphere over the King George Island. The most recent instrument installed at Comandante Ferraz, at the beginning of last year, was the meteor radar that is currently in operation through a collaborative effort between the Colorado Research Associates (CoRA), from United States, and National Institute for Space Research (INPE), from Brazil. The primary objective of this radar is to observe the wind structure between 80 and $100 \mathrm{~km}$ altitude. Besides the radar, other two airglow cameras (which belong to INPE) are in operation with the aim of monitoring the gravity wave activity in the mesosphere, and then characterize these waves, and observe the mesopause temperature structure. By using temperature observations it is possible to monitor the long term variability of the thermal structure, and conduct 

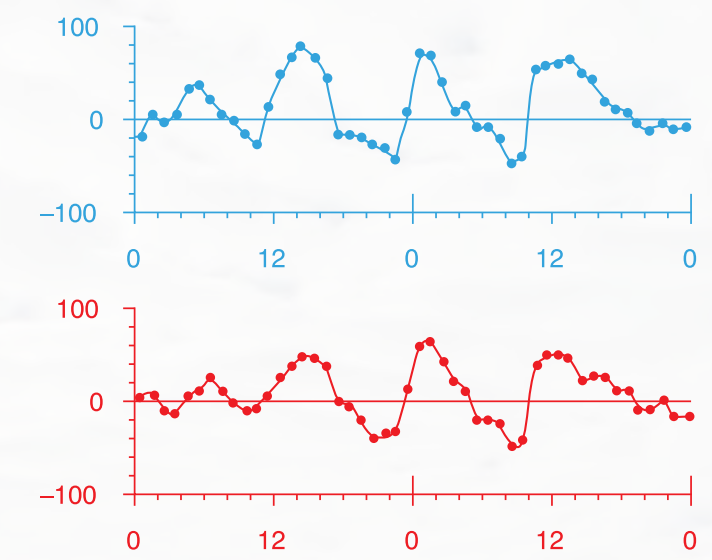

100
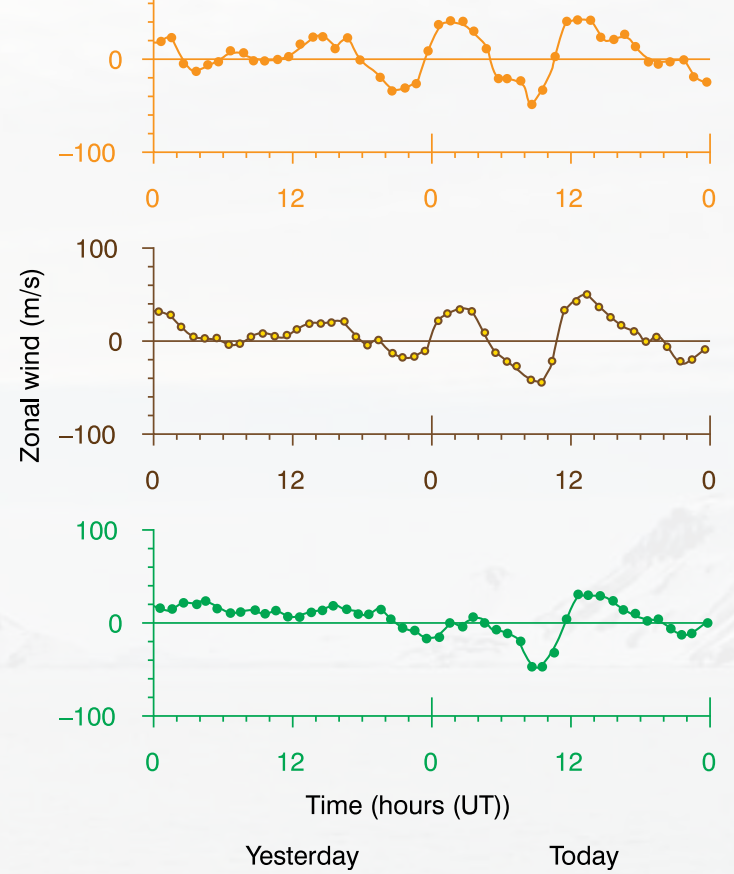

Frequency $(\mathrm{MHz})$

36.90
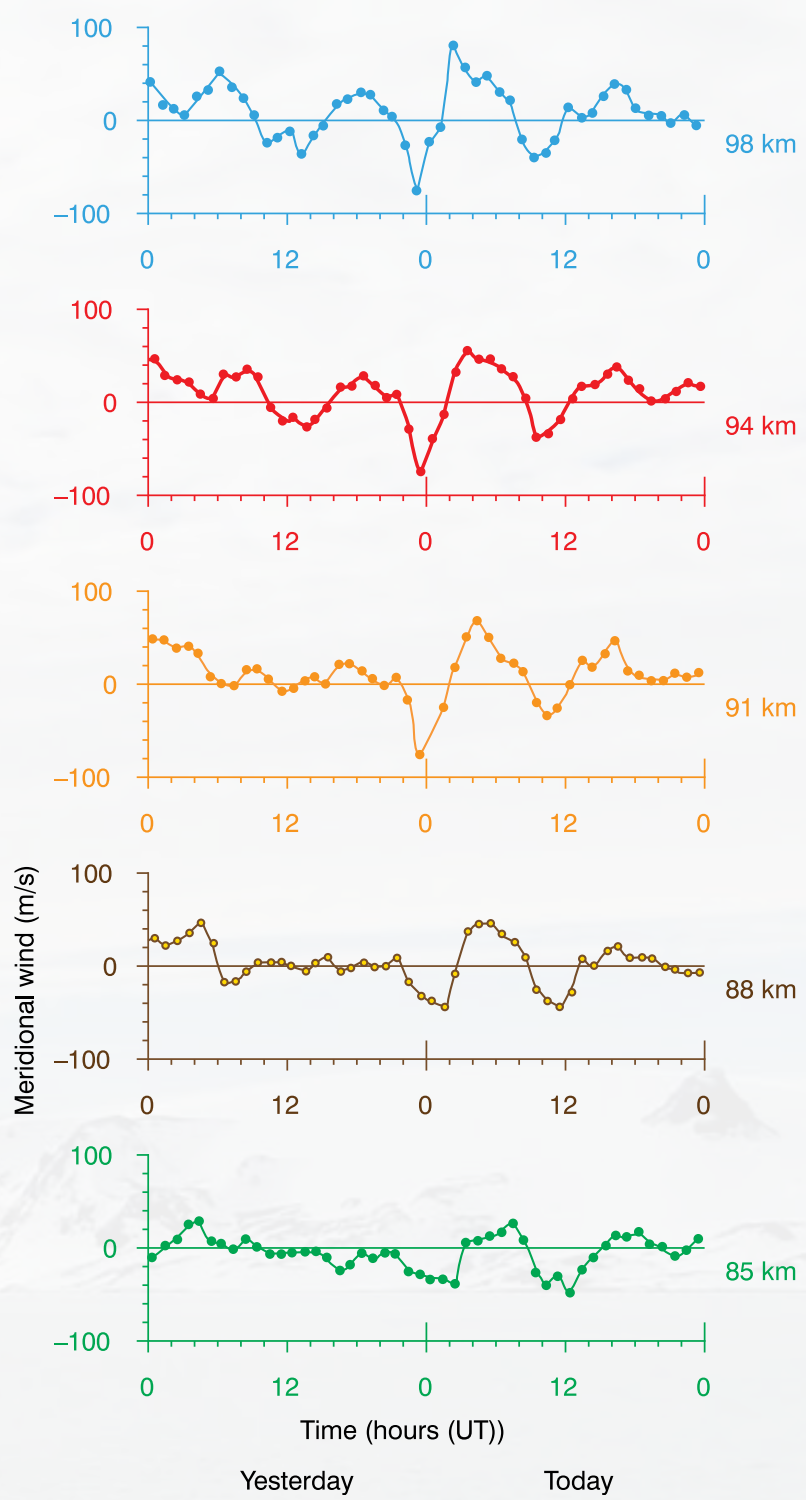

Figure 3. Examples of winds observed on 12-13 September 2010 by the meteor radar installed at Comandante Ferraz station in March 2010.

studies to identify signature of waves of different scales in the temperature and in its day-to-day variability. Future investigation will include the use of local winds, as observed by the meteor radar, to study the wave filtering process due to the background winds. Moreover, these winds also will be useful in investigations of the gravity wave sources with the reverse ray tracing modelling.

\section{Acknowledgements}

J. V. Bageston thanks to FAPESP for the post-doctorate fellowship under the process $n^{\circ}$ 2010/06608-2. This work was partially sponsored by the Brazilian Antarctic Program (PROANTAR/MMA, CNPq process n $n^{\circ}: 52.0186 / 06-0$ ), and INCT-APA (CNPq process n ${ }^{\circ}$ 574018/2008-5 and FAPERJ process $n^{\circ}$ E-16/170.023/2008). 


\section{References}

Bageston, J.V. (2010). Caracterização de ondas de gravidade mesosféricas na Estação Antártica Comandante Ferraz. Tese em Geofísica Espacial, Instituto Nacional de Pesquisas Espaciais. Available from: <http://www.inpe.br/biblioteca/>

Bageston, J.V.; Wrasse, C.M.; Gobbi, D.; Tahakashi, H. \& Souza, P. (2009). Observation of mesospheric gravity waves at Comandante Ferraz Antarctica Station (62S). Annales Geophysicae, 27(s/n): 2593-8.

Bageston, J.V.; Wrasse, C.M.; Hibbins R.E.; Batista, P.P.; Gobbi, D.; Tahakashi, H. Fritts, D.C.; Andrioli, V.F.; Fechine, J.; \& Denardini, C.M. (2011). Case study of a mesospheric wall event over Ferraz Station, Antarctica (62 ${ }^{\circ}$ ). Annales Geophysicae, 29(s/n): 209-19.

Fritts, D. C. \& Alexander, M.J. (2003). Gravity wave dynamics and effects in the middle atmosphere. Reviews of Geophysics, 41(1): 1-46.

Gardner, C. S. (1995). Introduction to aloha/anlc-93 - the 1993 airborne lidar and observations of the Hawaiian airglow airborne noctilucent cloud campaigns. Geophysical Research Letters, 22(20): 2789-92.

Nakamura, T.; Higashikawa, A.; Tsuda, T. \& Matsushita, Y. (1999). Seasonal variations of gravity wave structures in oh airglow with a CCD imager at Shigaraki. Earth Planets Space, 51(7-8): 897-906.

Nielsen, K. (2007). Climatology and case studies of mesospheric gravity waves observed at polar latitudes. PhD Thesis, Utah State University.

Nielsen, K.; Taylor, M.; Hibbins, R. \& Jarvis, M. (2009). Climatology of short-period mesospheric gravity waves over Halley, Antarctica ( $\left.76^{\circ} \mathrm{S}, 27^{\circ} \mathrm{W}\right)$. Journal of Atmospheric and Solar-Terrestrial Physics, 71(s/n): 991-1000.

Takahashi, H., Batista, P.P.; Buriti, R.A.; Gobbi, D.; Tsuda, N.T. \& Fukao, S. (1999). Response of the airglow OH emission, temperature and mesopause wind to the atmospheric wave propagation over Singaraki, Japan. Earth Planets and Space, 51(7-8): 863-75.

Taylor, M. \& Gardner, C.S. (1998). Observational limits for lidar, radar, and airglow imager measurements of gravity wave parameters. Journal of Geophysical Research, 103 (D6):6427-37. 